\title{
The Study of Modern Evolution of Rural Settlement pattern in Pearl River Delta: A Case study of Nanshe Village
}

\author{
Ying Pan ${ }^{1, a}$, Jinglu Ye $\mathrm{Y}^{2, \mathrm{~b}}$ \\ ${ }^{1}$ School of Architecture, South China University of Technology; State Key Laboratory of Subtropical \\ Building Science, South China University of Technology, Guangzhou, Guangdong, China \\ 2 School of Architecture, South China University of Technology, Guangzhou, Guangdong, China \\ a13380056897@163.com, b18680517657@163.com
}

Keywords: rural settlements pattern, Pearl River Delta Region, modern evolution Abstract. Under the influence of economic growth in contemporary and modern times, the rural settlement pattern in Pearl River Delta Region presents the features of rapid urbanization. This thesis illustrates a village as the case to make a diachronic study on rural pattern evolution and starts from a multi-disciplinary perspective to explore the influential factors of rural settlement pattern evolution in Pearl River Delta Region in different stages and corresponding evolution characteristics, with the view of offering references for future sustainable development of rural settlements.

\section{Introduction}

During the evolution process in contemporary and modern times, the economic pattern and social pattern of rural settlement in Pearl River Delta Region undergo drastic reformation and simultaneously stimulate relevant settlement spatial pattern to experience a rapid evolution process. [1] Anthropology and sociology respectively start from different perspectives to have the long-term tracking observation on some villages in this region and offer more clear historical clues for the study in this thesis.

The study case Nanshe village elected by the thesis is located in Putian region adjacent to Hanxi River, the branch of Dongjiang, in Chashan County of Dongguan City. Traditional rural layout forms a sharp contrast with industrial region triggered by economic growth in Pearl River Delta Region. As a consequence, Nanshe village has certain typicality as the target of rural settlement evolution in Pearl River Delta Region.

\section{Traditional Settlement (before 1949)}

2.1 Traditional Settlement Pattern in Nanshe Village. Before liberation, Nanshe village had flat terrain and tilted from southeast to northeast. It is adjacent to Nanshe Langshui system in the north and Dongjiang branch and Shipai in the south. Surrounded by the wall built in Ming Dynasty, the village is distributed in a symmetrical form. [2] In the horizontal direction from east to west, Nanshe village centers around a long-strip pool and in the longitudinal direction from south to north, the layout of residential dwellings complies with the ascent of terrain to present the pattern of lanes. With continuous boundaries and crossed lanes, a pool-centered village spatial pattern in a boat shape finally takes shape. After the development for thousands of years, Nanshe village develops into a single-surname village dominated by the Xie family. [3]

2.1.1 The Spatial Order of Traditional Settlement. Patriarchal Awareness - Nanshe village is a single-surname village dominated by the Xie family and most ancestral temples are built around the central pool in the village. Different from southern villages where the residential dwellings are built around different branches of ancestral temples, the residential dwellings in Nanshe villages are all built around the Xie Family Ancestral Temple regardless of branches and star-step features. This not only symbolizes the centrality and integrity, but also presents the distribution features of dwelling form under the harmonious patriarchal awareness.

Market Structure - In ancient history, Nanshe village had favorable economic conditions and surplus agriculture foods were often output to make transactions with surrounding central markets. 
Until the regime of Kangxi Emperor, 90\% agricultural products in Chashanxu were from Nanshe cillage. Later on, due to the powerful patriarchal power and rich material resources, Nanshe villagers were not subject to other clans and finally expelled from Chashanxu. In 1750, Nanshe village negotiated with nearby Dazhenpu to set up Dazhenxu in the form of shareholder. Villagers were allowed to set up stores here. Gradually, Dazhenxu became the communication space that connected the interior and exterior rural space. In terms of exterior village space, some villagers also set up some stores on the two sides of the central pool and ancestral temples. In this way, the fair space was integrated into the residential region.

Landscape Layout - Surrounding mountains of the village are grew with lichee trees. The luxuriant crops in the paddy field possess the typical appearance of traditional settlement landscape in Lingnan area. [4] The abundant Nanshe Lang river system enclosed by pomegranate dam in the north corresponds to the flourishing mountain vegetation and paddy fields in the south. In this sense, the location of Nanshe village faces the water with mountains on the back. The layout of boat-shape village reflects the desire for water resources.

\section{The Disappearance of Order Based on Economic Collectivization (1949-1978)}

3.1 Pattern Readjustment of Land Resources. As for the land reformation in the 1950s, the land of clans and landowners was confiscated and redistributed and the economic foundation of clans was destroyed. [5] The relative uniformity between clans and village land resources was broken out. In 1966, Agricultural Dazhai Movement simply emphasized crop plantation. Nanshe village started to engage in polderization, earth filling on Nanshe Lang water system, large paddy field reformation, and cultivated area expansion. All of these finally decreased water transportation advantages.

3.1.1 Emergence of Infrastructure Construction. The Great Leap Forward Movement placed high emphasis on water conservatory construction. Nanshe village builds Nanshe Lang irritation and drainage engineering in the north and transforms original water system into ditches by earth filling in the south. After the disappearance of large-scale water area, the village takes on a new dwelling pattern with pieces of cultivated land and paddy field. The water conservatory construction decreases flood disasters and improves productivity level. [6]Together with the start-up of urbanization process in Chashan County, Nanshe village does not have developed water-system transportation conditions but relies on road and railway transportation. Guangdong-Kowloon railway brings about potential geographical advantages for following economic growth of Nanshe village.

3.1.2 Deconstruction of Landscape Pattern. Nanshe Lang polderization transforms large-scale water area into cultivated land and dampens traditional geomantic pattern alongside mountain and water. The area of cultivated area continually increases and ranks the first place in overall Chashan county. However, since the economic growth during this period is relatively stagnant, dwelling construction basically remains in the sluggish state. The expansion of exterior dwelling form is less obvious. Few red-brick dwelling architectures around the wall inherits the traditional dwelling form in Ming and Qing Dynasty before liberation. In the same way, the village still preserves the limitations of village under the influence of wall.

\section{The Derivation of Dwelling Under the Stimulation of "Custom Manufacturing with Imported Materials" (1978-early 90s)}

4.1 Protection and Derivation of Traditional Core. Under the Influence of "custom manufacturing with imported materials" economic stimulus after the reform and opening-up, the economy in Nanshe village presented relatively obvious growth tendency. Driven by the start-up of industrial economy, numerous villages of Chashan County started the demolition and reconstruction work. Many residential dwellings and ancestral temples were pulled down or damaged with varying degrees. Due to the relatively backward economic growth in comparison with other villages, Nanshe village paid less attention to demolition in old villages. In early $80 \mathrm{~s}$, under the leadership of village committee and patriarchal power, Nanshe village claimed to protect traditional village core region within the wall 
and designed seven villager groups to construct surrounding dwelling bases. As a result, traditional architecture in villages was preserved during the demolition work. Later on, Nanshe village presented a circular derivation region based on the core protection area.

4.1.1 The Regeneration of Patriarchal Culture and Belief Culture. After the reform and opening-up, the power of patriarchal clan and belief ushered in moderate regeneration during this stage together with the weakening of state ideology. Inspired by the village committee and patriarchal power, Nanshe village started to renovate and reuse old ancestral temples and ancient temples. At the same time, the family worship activities abolished during Cultural Revolution period became popular once again and villagers started to serve oblations for ancestors. Moreover, the reclaim of the leadership of Xie family in village committee and the reorganization of village power institution represented the regeneration of patriarchal awareness to some degree. However, such patriarchal awareness at that time simply existed in ideologies. In other words, the patriarchal clans did not possess predominant right over economy and power based on land ownership as usual.

4.1.2 Early Prototype of Industrial Land. In the 80s, the introduction of companies engaged in "custom manufacturing with imported materials" promoted the rapid development of industries in Chashan County. Due to the geographical advantage close to Hong Kong and Macao, Chashan attracted lots of Hong Kong merchants to build factories here. At this time, labor-intensive manufacturing companies mostly utilized original residential space as the workshop and few public architectures as the warehouse. In the meanwhile, then village committee commanded the approval right of partial land usage. According to the decisions of the village committee, the residential land was redistributed and partial agricultural land was used for factories, business districts and rental properties. After the rural industrialization in the 80 s, the land nearby the southern railway line was classified as industrial land. However, the factories were not centralized with regard to distribution but inserted into norther residential area in the form of functional resetting. The discrete form of settlements was not so obvious.

\section{Settlement Expansion Driven by Industrial Impetus (from mid and late 90s -now)}

5.1 Expansion of Industrial Layout. After the 90s, the industrial development in Nanshe village gradually turned mature and industrial park construction spurred by economic growth became the focus. Moreover, the administration planning power of the village committee also progressively moved from basic residential construction to industrial park construction. In 1992, the village committee made unified planning and construction of Jinshan industrial region on the southwestern side of Guangdong-Kowloon railway and Chanan Road based on original spare factory distribution bases. Original mountain forests were replaced by the new industrial region and business districts on the southern side of Guangdong-Kowloon railway. After 2000, Nanshe village successively developed the Wanfuling Industrial Region in the east and Hongmian Industrial Region on the southwestern side of ancient villages. Due to the obscure boundary between industrial region and adjacent villages, traditional villages and industrial regions formed a sharp contrast along the Guangdong-Kowloon railway within the territory of administration village. Subsequently, new business streets and market structure appeared in the industrial region.

5.1.1 Division of Village Space. After the shaping of three major industrial regions, the village committee retained experts to design the specific protection plan for ancient villages in 2003 . The village committee plans the ancient village landscape region by taking the walls built in Ming and Qing Dynasty as the boundary and reusing the restrictive properties of walls. [7]To be sure, the implications of boundary totally change, excluding any prevention attributes or dynamic restrictions. Moreover, no residents choose to live within the landscape region. Some ancestral temples maintain traditional worship habits and convert to cultural exhibition halls and leisure activity centers. Besides few foreign immigrant workers, old villagers live in the derivation region outside the wall. Most residents who live in the industrial region with supporting business district and leisure park shared with adjacent villages are immigrant population. As a result of the construction of 
Guangdong-Kowloon railway, there appears a transitional space between industrial region and traditional village. The form and users of three-layer space have shown apparent division.

5.1.2 Decline of Regional Features. From the perspective of living conditions, the residential architecture at this time transforms from traditional bungalows to buildings with cement and concrete structure and adopts specific patterns, construction techniques and materials different from traditional practices. The residential center of the fish hatchery in Jinshan Industrial Region even implements a totally urbanized community management mode. As for residential dwelling form, the residential architecture presents more commonness and unity instead of localization and tradition, which implies the impacts and growing collapse of traditional aesthetic values.

5.1.3 Extinction of Cultivated Land Resources. Nanshe village has relatively large area and rich land resources. But at this time, the area of cultivated land continues to decrease due to the express construction in the east and project activities such as Dongguan ecological park requisition. The appropriation of industrial region, the disappearance of cultivated land and the insufficiency of residential foundation hamper the sustainable development process of the traditional agriculture in Nanshe village but manifest the coexistence of urbanization and loss of rural characteristics. At the same time, traditional villages lose the development impetus for internal industries but follow an economic mode which transforms cultivated land into industrial factories and relies on land rents. [8]

\section{Conclusion}

During the modern and contemporary process for nearly hundreds of years, the settlement space form in Nanshe village takes place tremendous changes, changes previous slow and progressive evolution means and manifests the features of transitional society. Once summarizing the evolution of Nanshe village, the law of evolution could be concluded as follows. After separating the economic state which relies on agriculture, Nanshe village improves industrial development and residential levels at the cost of cultivated land. The expansion of settlements limited by modern road transportation network presents duality features together with original villages and loses integrity. The settlement evolution breaks through original geomantic pattern and spatial diversity. Moreover, the functional division mode under market economic values also goes on a flattening tendency. All of these imply the drastic reformations under the economic stimulus of "Custom Manufacturing with Imported Materials" in Pearl River Delta Region and highlight the symbiotic relationship between industrial reformation and villages characteristic of mutual independence and mutual contradiction.

\section{References}

[1] Ying Shi, Ying Pan: South Architecture No. 03(2011), P. 70-78 In Chinese

[2] Qi Lu: Journal of Guangdong Landscape Architecture No. 01(2013), P.77-80 In Chinese

[3] Qiong Zhou: Globalization and Rural Change - The Practice of the South Village in the Pearl River (The Commercial Press, Beijing 2012). In Chinese

[4] Xiannong Dong, Jing Wang, Biao Liu: Journal of Guangdong Landscape Architecture No. 02(2015), P.16-19 In Chinese

[5] Ying Pan, Xianlan Zhuo, Ying Shi: South Architecture No. 03(2015), P. $71-78$ In Chinese

[6] Li Li: Rural Settlement: Form, Type and Evolution - A Case Study of Jiangnan Area (The Commercial Press, Beijing 2012) In Chinese

[7] Jianhong Fan, Hong Ni: Architectural Journal No. S1(2012), P. 177-181 In Chinese

[8] Daming Zhou: Bid Farewell to Local Society (The Commercial Press, Beijing 2012) In Chinese 